УДК 343.13

DOI 10.18101/2658-4409-2020-1-60-71

\title{
ГРАЖДАНСКИЙ ИСК КАК СРЕДСТВО РЕАЛИЗАЦИИ ВОССТАНОВИТЕЛЬНОГО ПОДХОДА В УГОЛОВНОМ СУДОПРОИЗВОДСТВЕ
}

\section{(C) Попова Ирина Павловна}

кандидат юридических наук, доцент, Восточно-Сибирский институт МВД России

Россия, 664074, г. Иркутск, ул. Лермонтова, 110

E-mail: irinabaikal@mail.ru

Статья посвящена актуальным проблемам гражданского иска в уголовном судопроизводстве. Возмещение ущерба, причиненного преступлением, наряду с разрешением уголовного дела по существу сопряжено с рядом трудностей. В статье рассматриваются проблемные вопросы правовой природы гражданского иска, возникающего вследствие причинения вреда преступлением, принадлежности гражданского иска уголовно-процессуальному праву, понятия иска и характерные черты исковой формы защиты права, проблемы срока исковой давности. Автором обоснован вывод о необходимости не только сохранения института гражданского иска в уголовном процессе, но и расширения его оснований. Одной их актуальных является проблема субсидиарного применения норм других отраслей права при рассмотрении гражданского иска в уголовном деле. Обсуждается вопрос пределов применения других отраслей права с учетом публичности уголовного судопроизводства и придания определенной публичности и гражданскому иску в уголовном деле, что исключает расширение возможностей проведения бесед, не предусмотренных уголовно-процессуальным законом.

Ключевые слова: восстановительное правосудие; гражданский иск в уголовном процессе; судебная защита; возмещение ущерба, причиненного преступлением; предмет и основание гражданского иска в уголовном деле.

\section{Для цитирования}

Попова И. П. Гражданский иск как средство реализации восстановительного подхода в уголовном судопроизводстве // Вестник Бурятского государственного университета. Юриспруденция. 2020. Вып. 1. С. 60-71.

Одной из ключевых задач государственной деятельности в уголовном судопроизводстве обоснованно рассматривается реализация восстановительного подхода к нарушенным преступлением правоотношениям в состояние «до прежнего», восстановление нарушенной социальной справедливости. Традиционно реализация интересов потерпевшего и граждан- 
И. П. Попова. Гражданский иск как средство реализации восстановительного подхода в уголовном судопроизводстве

ского истца в указанной части рассматривается в качестве частных интересов.

Между тем в государстве должны быть созданы и только лишь при поддержке государства могут реализовываться механизмы обеспечения защиты нарушенных преступлением прав граждан. Тем самым обеспечивается доступ потерпевших к правосудию для защиты нарушенных прав и их восстановления. Одним из процессуальных средств, способных достичь решения указанных задач, является обеспечение возмещения вреда, причиненного преступлением.

Т. Е. Сушина справедливо отмечает, что «мировая тенденция развития восстановительного правосудия, которая благодаря глобализации не могла не затронуть сферу российского уголовного судопроизводства, привела к наполнению института гражданского иска в уголовном деле новым содержанием» $[15$, с. 103].

Восстановление нарушенных преступлением прав потерпевшего может быть достигнуто в результате нескольких форм: 1) гражданский иск в уголовном процессе; 2) фактическое возвращение имущества его владельцу (собственнику); 3) добровольное возмещение вреда его причинителем.

Если фактическое возвращение похищенного имущества возможно и вне воли обвиняемого, к примеру в результате мер, принятых в ходе досудебного производства органами, осуществляющими предварительное расследование, то такая форма как добровольное возмещение вреда обвиняемым может быть как итогом позитивного постпреступного поведения, так и результатом применения восстановительных технологий.

Универсальным средством защиты имущественных прав потерпевшего от преступления является институт гражданского иска в уголовном судопроизводстве. Установленная законом возможность совместного рассмотрения гражданского иска и уголовного дела обусловлена наличием единого юридического факта, лежащего в основе привлечения лица к уголовной и гражданско-правовой ответственности в тех случаях, когда преступлением причинен материальный ущерб или моральный вред. Отдельные исследователи напрямую рассматривают возмещение имущественного вреда потерпевшему как элемент справедливости [12, с. 109].

Требование о возмещении материального вреда (компенсации морального вреда) может быть рассмотрено и в порядке гражданского судопроизводства. Однако совместное рассмотрение уголовного дела и гражданского иска создает ряд преимуществ. В частности, способствует полному и всестороннему исследованию доказательств и обеспечению более быстрого восстановления нарушенных прав и законных интересов граждан и юридических лиц, создает оптимальный процессуальный режим для суда и сторон, способствует материальной и процессуальной экономии. 
Как верно отмечает В.С. Шадрин для установления содержания и размера причиненного вреда, обеспечения его возмещения привлекается аппарат органов расследования, используются возможности оперативноразыскной деятельности, применения мер уголовно-процессуального принуждения. По его мнению, лицо, предъявившее в уголовном деле иск о возмещении причиненного преступлением вреда, оказывается в более выигрышном положении в сравнении в его положением в гражданском процессе, поскольку задействован весь арсенал средств раскрытия и расследования преступлений [16, с. 152].

Отказ законодателя от предоставленной в УПК РСФСР 1960 г. (ч. 4 ст. 29) возможности суду по своей инициативе разрешать вопрос о возмещении ущерба свидетельствует об усилении диспозитивных начал в предоставлении сторонам возможности самостоятельно распоряжаться своими правами. Вместе с тем реализация диспозитивных начал в части возмещения ущерба, причиненного преступлением, не может происходить вне определенной доли влияния на данные вопросы органов, осуществляющих уголовное преследование, и суда. Кроме того, рассмотрение гражданского иска в уголовном процессе придает ему некие черты публичности, обусловленные обязанностью разъяснить право на заявление гражданского иска, принятия мер к обеспечению иска и другое. В частности, мировое соглашение в уголовном процессе не влечет прекращения производства по делу, так как подлежит проверке и оценке в том же порядке, как и признание подсудимым своей вины, и не освобождает от доказывания факта совершения преступления, причинившего вред, и размера вреда.

Так как институт гражданского иска в уголовном процессе является комплексным правовым институтом, субсидиарное применение норм других отраслей права вызывает некоторые вопросы в правоприменительной деятельности. Так, одним из дискуссионных вопросов является исковая давность гражданского иска в уголовном процессе. На основании ст. 204 ГК РФ, если судом оставлен без рассмотрения иск, предъявленный в уголовном деле, начавшееся до предъявления иска течение срока исковой давности приостанавливается до вступления в законную силу приговора, которым иск оставлен без рассмотрения. Данная норма вызывает противоречивую судебную практику. Так, ряд судов считает, что срок исковой давности для предъявления иска в порядке гражданского судопроизводства исчисляется с момента вступления в законную силу приговора или с момента его вынесения [2, с. 10].

Одной из обсуждаемых проблем является вопрос о расширении пределов иска в уголовном процессе. Кроме названных существуют и некоторые другие вопросы и проблемы как в теории гражданского иска в 
И. П. Попова. Гражданский иск как средство реализации восстановительного подхода в уголовном судопроизводстве

уголовном процессе, так и в практике его применения. Наиболее полно вопросы гражданского иска разработаны в юридической литературе советского периода, УПК РФ 2001 г. не только не решил существующие проблемы, но и обозначил новые. Учение об иске как основной институт гражданского процесса урегулирован нормами этой отрасли права. Однако следует заметить, что некоторые вопросы учения об иске являются спорными и в гражданском процессе. К примеру, на протяжении длительного времени спорным является вопрос о значимости материальноправового содержания искового требования и в связи с этим о принадлежности иска к материальным или процессуальным отраслям права.

Так, А. А. Добровольский в своих работах выделял три точки зрения на понятие иска: 1) иск - понятие чисто процессуальное, и потому может быть только одно понятие иска - только как обращение к суду как средство возбуждения процесса; 2) иск в процессуальном смысле есть средство защиты права, а в материальном - есть само защищаемое судом право; 3) в едином понятии иска наличествует две стороны: требование к суду о защите права составляет процессуальную сторону иска, связанную с требованием истца к ответчику, которое имеет материально-правовое значение $[6$, с. $8,15,23 ; 7$, с. 12]. Представляется, что под иском следует понимать требование юридически заинтересованного лица (истца), обращенное к суду первой инстанции, о защите нарушенного или оспариваемого субъективного права или охраняемого законом интереса установленным законом способом на основании указанных фактов, с которыми оно связывает неправомерные действия ответчика.

При разрешении большинства споров о праве основной формой защиты является исковая, для которой характерны следующие черты:

«1) порядок разбирательства и разрешения гражданских дел точно установлен законом;

2) заинтересованные в деле лица имеют право участвовать в разбирательстве дела;

3) лицам, участвующим в деле, предоставляются определенные права, определенные гарантии, называемые процессуальными правами (право давать объяснения по делу, представлять доказательства, заявлять различные ходатайства и т. п.);

4) решение по делу должно быть основано на законе и фактах, установленных судом в судебном заседании, определенным в законе способом» $[6$, с. $49-50]$.

Сущность исковой формы защиты права состоит в том, что разрешение иска подлежит рассмотрению с обязательным соблюдением установленной законом процессуальной формы. 
Еще одним спорным вопросом учения об иске является число элементов иска и отличительные черты каждого из них. Бесспорными считаются два элемента иска - предмет и основание. Некоторые процессуалисты считают, что иск состоит из трех частей (элементов): предмета иска, основания иска и содержания иска. А. Г. Мазалов указывает, что «предметом гражданского иска является обращенное к суду требование истца к обвиняемому (гражданскому ответчику) о принудительной передаче вещи или денег в качестве возмещения за вред, причиненный преступлением» $[11$, c. 25$]$. Под содержанием иска он понимают указанную истцом форму судебной защиты права - присуждение или признание. Длительное время существовало убеждение, что в уголовном процессе возможен только иск о присуждении, то есть о восстановлении нарушенного права [11, c. $37-40]$.

Так, В. С. Шадрин считает, что если иметь в виду установление и возможное без ущерба для разрешения основного вопроса уголовного дела устранение последствий преступления в виде непосредственно причиненного преступлением имущественного и морального вреда, то использование возможностей стадии расследования совершенно оправданно и необходимо.

Но вместе с тем указанный автор считает, что нерентабельно использовать силы и средства расследования для осуществления деятельности, не связанной непосредственно с раскрытием и расследованием преступления, при наличии для лица реальной возможности удовлетворить свои имущественные интересы в порядке гражданского судопроизводства $[16$, c. 152].

Более широкие возможности для взыскания не только прямого ущерба, причиненного преступлением, но и упущенной выгоды, рассматривают другие авторы [13, с. $45 ; 1$, с.11-12; 9, с. 33-36].

Содержание иска определяется его целью и свидетельствует о характере требований истца к суду [14, с. 46-52]. Сторонники другой точки зрения считают, что такое понимание содержания иска вполне охватывается его предметом и исключает необходимость обосновывать содержание иска как его самостоятельный элемент [6, с. 125]. Спорным является и понятие предмета иска в целом. Понятие предмета и основания иска имеют решающее значение для характеристики иска, поскольку в значительной мере элементы иска предопределяют объем и направление исследования дела в суде, из них легко усмотреть, какие доказательства необходимы по делу. Важное значение имеет содержание элементов иска и для решения вопроса о возможности изменения иска в ходе процесса.

Обычно иски рассматриваются в порядке гражданского судопроизводства. Но если истец требует возмещения (компенсацию) за вред, при- 
И. П. Попова. Гражданский иск как средство реализации восстановительного подхода в уголовном судопроизводстве

чиненный ему преступлением, то, согласно закону, он вправе предъявить свой иск при производстве по уголовному делу, с тем чтобы он был рассмотрен и разрешен одновременно с последним (ч. 1 ст. 44 УПК РФ). Такой иск именуется гражданским иском в уголовном деле или гражданским иском в уголовном процессе. В правовой литературе существует несколько точек зрения на вопрос о принадлежности института иска к той или иной отрасли процессуального права [3, с. 72,5, с. 14].

Следует разделить точку зрения о принадлежности гражданского иска в уголовном деле к уголовно-процессуальному институту, регулирующему деятельность участников уголовного судопроизводства по поводу последствий преступления именно в процессе расследования, рассмотрения и разрешения уголовных дел. В уголовном судопроизводстве уголовнопроцессуальные отношения несут и производную задачу реализации гражданско-правовых отношений, возникших в связи с преступлением. Совокупность правовых норм, образующих институт гражданского иска, регулирует непосредственно не материально-правовые отношения, а лишь поведение участников уголовного судопроизводства по поводу этих отношений. Поскольку рассмотрение гражданского иска представляет собой по существу отдельное производство, порядок которого подробно регламентирован нормами гражданского процесса, то является целесообразным учет предписаний ГПК РФ. При этом при рассмотрении иска гражданско-процессуальные нормы могут применяться лишь по вопросам, не урегулированным уголовно-процессуальным правом, и в пределах, не противоречащих нормам уголовного процесса, причем последние в данном случае являются приоритетными.

В связи с чем представляется спорным предложение такого субсидиарного применения норм гражданского процесса, которое предусматривает возможность проведения не предусмотренной УПК РФ беседы с гражданским истцом с целью убедиться в наличии минимально необходимых документов, а в случае отсутствия данных для исследования иска предложить истцу решать данный вопрос в порядке гражданского судопроизводства.

Так, В. Горобец предлагает провести подобную беседу до начала судебного заседания в присутствии секретаря судебного заседания и полагает, что в случае если истец не согласится с такой позицией, то суд обязан рассмотреть вопрос о принятии исковых требований к рассмотрению либо отказе в этом с вынесением определения на месте либо с удалением в совещательную комнату [4, с. 47-49]. Между тем уголовнопроцессуальный закон проведение такой беседы не предусматривает, а на стадии назначения дела к судебному заседанию возможно лишь проведение предварительного слушания, причем только в случаях, прямо преду- 
смотренных в законе (ст. 229 УПК РФ), к которым разрешение вопросов о принятии гражданского иска не относится.

Доказывание гражданского иска в уголовном процессе производится по правилам, установленным в уголовно-процессуальном законе. Подсудность гражданского иска определяется подсудностью уголовного дела, в котором он предъявлен (ч. 10 ст. 31 УПК РФ). В уголовном процессе (в отличие от гражданского) не допускается подача встречного иска, т. е. обвиняемый может быть только лицом, отвечающим по иску, но не может быть гражданским истцом в том же деле. Определяется это тем, что встречный иск имел бы основанием иной юридический факт, но не преступление, в совершении которого обвиняется обвиняемый. Этим объясняется также и то, что при объединении в одном производстве встречных заявлений по делам частного обвинения подача встречного иска возможна, т. к. в данной ситуации каждый из исков будет иметь своим основанием деяние, являющееся преступлением [10, с. 197].

Требование о возмещении (компенсации) вреда, причиненного преступлением, носит личный характер. Поэтому в уголовном процессе невозможна уступка требования по иску другому лицу. Юридические факты, из которых истец выводит свои требования и с наличием которых закон связывает возникновение правоотношения между истцом и гражданским ответчиком, составляют основание иска. Таким фактами являются: 1) совершение преступления (общественно опасного деяния), 2) наличие вреда на стороне истца, 3) причинная связь между преступлением (общественно опасным деянием) и вредом.

Конституционный суд Российской Федерации неоднократно подчеркивал, что обязанность возместить причиненный вред как мера гражданско-правовой ответственности применяется к причинителю вреда при наличии состава правонарушения, включающего, как правило, наступление вреда, противоправность поведения причинителя вреда, причинную связь между противоправным поведением причинителя вреда и наступлением вреда, а также его вину ${ }^{1}$.

Суд не может в уголовном деле рассматривать исковые требования о возмещении вреда, причиненного такими действиями, которые преступными не являются и обвиняемому не вменяются. Оставление иска без рассмотрения не препятствует обращению с ним вновь в порядке граж-

\footnotetext{
${ }^{1}$ Об отказе в принятии к рассмотрению жалобы гражданина Уткина Алексея Васильевича на нарушение его конституционных прав частями второй и третьей статьи 159 , частью третьей статьи 159.1 Уголовного кодекса Российской Федерации, а также частью второй статьи 243 и частью второй статьи 309 Уголовно-процессуального кодекса Российской Федерации: Определение Конституционного Суда РФ от 27.03.2018 г. № 834-О. Доступ из справ.-правовой системы «КонсультантПлюс».
} 
И. П. Попова. Гражданский иск как средство реализации восстановительного подхода в уголовном судопроизводстве

данского судопроизводства, так как отсутствие в действиях лица, привлекавшегося к уголовной ответственности, признаков преступления не всегда означает отсутствие гражданского правонарушения.

Следует также иметь в виду, что праву известны обстоятельства, которые исключают противоправность деяния, хотя они внешне обладают всеми признаками противоправного. К таким обстоятельствам относятся состояния необходимой обороны и крайней необходимости. Необходимая оборона исключает не только уголовную, но и гражданскую ответственность. При превышении пределов необходимой обороны причинитель обязывается к возмещению вреда в полном объеме или частично с учетом вины потерпевшего. Если оправдательный приговор постановляется ввиду установления судом факта, что подсудимый действовал в состоянии необходимой обороны и не превысил ее пределов, то, очевидно, нет смысла оставлять заявленный гражданский иск без рассмотрения, поскольку и в порядке гражданского судопроизводства истец не сможет получить возмещения.

Другим обстоятельством, исключающим противоправность деяния, является совершение преступления в состоянии крайней необходимости. Причем в отличие от уголовного законодательства, гражданское устанавливает, что вред, причиненный в состоянии крайней необходимости, должен быть возмещен лицом, его причинившим. С учетом обстоятельств, при которых был причинен такой вред, суд может возложить обязанность его возмещения на третье лицо, в интересах которого действовал причинивший вред, либо освободить от возмещения полностью или частично как это третье лицо, так и причинителя вреда.

Без рассмотрения остаются иски при прекращении дела по основаниям, исключающим возможность уголовного преследования лица, совершившего общественно опасное деяние, например в случае смерти обвиняемого, недостижения установленного возраста уголовной ответственности.

Некоторые ученые и практики высказываются за ликвидацию института гражданского иска в уголовном процессе, мотивируя это нижеследующим. По их мнению, природа гражданского иска не соответствует сущности уголовного процесса, направленного на реализацию уголовной ответственности или освобождение от нее в установленных законом случаях. Гражданско-правовой спор основывается на презумпции виновности, при которой каждая из сторон обязана доказывать те обстоятельства, на которые ссылается, в то время как уголовное судопроизводство основано на презумпции невиновности обвиняемого и органы уголовного судопроизводства не вправе на него перелагать обязанности доказывания. При рассмотрении гражданского иска одновременно с уголовным делом требуется применение норм права по аналогии или более полная регламентация процедуры рассмотрения иска. 
Однако, несмотря на то, что следователи и судьи зачастую не уделяют должного внимания рассмотрению гражданского иска, расценивая его как нечто второстепенное относительно уголовного обвинения, оснований для такого подхода не имеется.

Так, согласно ст. 73 УПК РФ, характер и размер ущерба, причиненного преступлением, входят в круг обстоятельств, которые необходимо установить, и подлежат обязательному доказыванию. По делам об имущественных преступлениях вопросы гражданского иска, как правило, непосредственно вытекают из объема обвинения (например, в части количества похищенного имущества или его оценки) и юридической оценки преступных действий по соответствующим статьям уголовного закона (например, в зависимости от умышленной или неосторожной формы вины причинения вреда в состоянии необходимой обороны или крайней необходимости). Не менее актуальны эти обстоятельства и по делам о преступлениях против личности, применительно к которым подлежат установлению, в частности, сведения о степени физических, нравственных страданий, в обоснование исков о компенсации морального вреда.

Преступление может вызвать самые различные последствия. Уголовно-правовые последствия преступления, выражающиеся в причинении вреда охраняемым уголовным законом отношениям, влекут применение уголовно-правовой ответственности. Гражданский иск в уголовном процессе направлен на восстановление прежде всего имущественных прав потерпевшего и компенсацию причиненного морального вреда. Для всесторонней защиты и восстановления прав потерпевшего представляется необходимым использовать в полной мере все правовые средства, в том числе и возможность предъявления гражданского иска.

Гражданский иск в уголовном процессе возможен, прежде всего, потому, что деяние лица противоречит нормам как уголовного, так и гражданского права, является основанием как уголовно-правовой, так и гражданско-правовой ответственности. Одно только единство этих оснований свидетельствует о допустимости рассмотрения гражданского иска в уголовном процессе. Помимо процессуальной экономии, рассмотрение гражданского иска обеспечивает наиболее быстрое восстановление нарушенных прав потерпевшего, способствует недопущению противоречивых выводов по одним и тем же вопросам. Разрешение в уголовном процессе гражданского иска помогает уточнить квалификацию преступления, в случае назначения наказания - правильно выбрать его вид и меру, установить гражданско-правовые последствия преступления, принять меры к их устранению. Предъявление иска на стадии предварительного расследования более эффективно, чем в порядке гражданского судопроизводства, способствует защите прав потерпевших, гражданских истцов. 
И. П. Попова. Гражданский иск как средство реализации восстановительного подхода в уголовном судопроизводстве

Несомненно, что процедура рассмотрения гражданского иска в уголовном процессе требует дополнительного законодательного регулирования, что тем не менее не позволяет ставить вопрос об исключении данного института из уголовного процесса. Поскольку институт гражданского иска в уголовном процессе - необходимый элемент, обеспечивающий реализацию одного из основных прав граждан - права на судебную защиту, и выступает одним из процессуальных средств реализации восстановительного правосудия.

\section{Литература}

1. Азаров В. Н., Супрун С. В. Охрана имущественных интересов личности в сферах оперативно-розыскной и уголовно-процессуальной деятельности. Омск: Изд-во Омской акад. МВД России, 2001. 266 с.

2. Беспалов Ю. Ф., Гордеюк Д. В. Гражданский иск в уголовном судопроизводстве: учеб.-практ. пособие. М.: Проспект, 2014. 168 с.

3. Божьев В. П. Гражданский иск в уголовном деле и применение гражданского процессуального права // Советское государство и право. 1986. № 8. C. 72-79.

4. Горобец В. Особенности рассмотрения гражданского иска в уголовном процессе // Российская юстиция. 2001. № 1. С. 47-49.

5. Даев В. Г. Современные проблемы гражданского иска в уголовном процессе. Л.: Изд-во ЛГУ, 1972. 71 с.

6. Добровольский А. А. Исковая форма защиты права. М.: Изд-во МГУ, 1965. $190 \mathrm{c.}$

7. Добровольский А. А., Иванова С. А. Основные проблемы исковой формы защиты права. М.: Изд-во МГУ, 1979. 159 с.

8. Зинатуллин 3. 3. Возмещение материального ущерба в уголовном процессе. Казань: Изд-во Казанского ун-та, 1974. 100 с.

9. Кривощеков Н. В. Гражданский иск в уголовном судопроизводстве. Тюмень: Изд-во Тюменского юр. ин-та МВД России, 2008. 127 с.

10. Куцова Э. Ф. Уголовный процесс: учебник / отв. ред. К. Ф. Гуценко. М.: Зерцало, 2007. 736 с.

11. Мазалов А. Г. Гражданский иск в уголовном процессе. М.: Юридическая литература, 1977. $176 \mathrm{c}$.

12. Муратова Н. Г., Хасаншина Р. Г. Сущность и значение возмещения вреда потерпевшему при принятии процессуальных решений по уголовным делам. М.: Юрлитинформ, 2016. 192 с.

13. Нор В. Т. Защита имущественных прав в уголовном судопроизводстве. Киев: Выща школа, 1989. 275 с.

14. Пучинский В. К. Элементы иска в советском гражданском процессе // Советское государство и право. 1979. № 3. С. 46-52. 
ВЕСТНИК БУРЯТСКОГО ГОСУДАРСТВЕННОГО УНИВЕРСИТЕТА

15. Сушина Т. Е. Современное состояние и перспективы гражданского иска в уголовном процессе // LEX RUSSICA. 2019. № 3(148). С. 100-107.

16. Шадрин В. С. Обеспечение прав личности при расследовании преступлений. М.: Юрлитинформ, 2000. 232 с. 
И. П. Попова. Гражданский иск как средство реализации восстановительного подхода в уголовном судопроизводстве

\section{CIVIL ACTION AS A MEANS FOR IMPLEMENTING A RESTORATIVE APPROACH IN CRIMINAL COURT PROCEEDINGS}

\section{Irina P. Popova}

Cand. Sci. (Law), A/Prof.,

East-Siberian Institute of the Ministry of Internal Affairs of Russia

110 Lermontova St., Irkutsk, Russia

E-mail: irinabaikal@mail.ru

The article is devoted to actual problems of a civil lawsuit in criminal proceedings. Compensation for damage caused by the crime, along with the resolution of the criminal case on the merits, is fraught with a number of difficulties. The article discusses the problematic issues of the legal nature of a civil lawsuit arising as a result of harm to a crime, whether a civil lawsuit belongs to criminal procedural law, the concepts of a lawsuit and the characteristic features of a lawsuit's form of protection of law, problems of the limitation period. The author substantiates the conclusion that it is necessary not only to maintain the institution of a civil lawsuit in criminal proceedings, but also to expand its grounds. One of their urgent is the problem of subsidiary application of the norms of other branches of law when considering a civil suit in a criminal case. The issue of the limits of application of other branches of law is discussed, taking into account the publicity of criminal proceedings and giving certain publicity and a civil lawsuit in a criminal case, which excludes the expansion of the possibilities for conducting conversations not provided for by the criminal procedure law.

Keywords: restorative; justice; civil lawsuit in criminal proceedings; judicial protection; compensation for damage caused by a crime; subject and basis of a civil lawsuit in a criminal case. 